\title{
Primary Small Intestinal Lymphoma: A Rare Case Report of Large B Cell Lymphoma Presentation as Intestinal Obstruction
}

\author{
Saeed Noman* \\ Oncologist, National Oncology Center-Aden, Yemen \\ *Corresponding author: Saeed Abdullah Ahmed \\ Noman, Clinical Oncology and Nuclear Medicine \\ Specialist, Director of Radiotherapy Management, \\ National Oncology Center-Aden, Yemen
}

Received: November 08, 2021; Accepted: November 30, 2021; Published: December 07, 2021

\begin{abstract}
Primary Gastrointestinal Lymphoma (PGIL) is the commonest Extranoda Lymphoma (ENL), which accounts for $30 \%-40 \%$. It is important to understand them and keep them in mind in differential diagnosis in daily clinical practice. Men are more frequently affected than are women. The clinical presentation of gastrointestinal lymphoma is frequently associated with pain, masses, perforations and obstructions. We are reporting the case of a young woman with intestinal obstruction diagnosed as Diffuse Large B Cell Lymphoma (DLBCL).
\end{abstract}

Keywords: Primary gastrointestinal lymphoma; Extranodal lymphoma; Intestinal obstruction; Diffuse Large B Cell Lymphoma

\section{Introduction}

Lymphoma is a heterogeneous malignancy, showing a highly variable outcome especially for the primary gastrointestinal lymphoma (PGIL) [1].

Primary intestinal lymphoma principally affects the digestive tract. In almost all cases, the intestinal lymphoma is a non-Hodgkin's Lymphoma (NHL) [2]. Primary gastrointestinal NHL accounts for 30-40\% of all extranodal NH [3]. Primary Intestinal Lymphoma (PIL) is a male predominant disease, and male:female ratio was 2.5:1 [4]. Stage and age were prognostic factors in many reports and the size of the mass were also mentioned [5]. The etiology of PGIL is still not clear, autoimmune diseases, some immunosuppressive agents, Helicobacter pylori infection, high protein and high fat diet, environmental pollution are associated with increased incidence [6]. Most common part of small intestine affected by lymphoma is ileum followed by jejunum and duodenum [7]. In most series of published literature, surgery was followed by adjuvant multiagent chemotherapy (CHOP) which has led to improved outcomes [8].

\section{Case Presentation}

A 20 years old woman presented with abdominal pain and discomfort for several months, she went to the several doctors without proper diagnosis. She was associated with fever and weight loss, no any peripheral lymph nodes are palpable, no hepatosplenomegaly. Her medical history was unremarkable. No history of $H$. pylori infection. Laboratory tests of blood were elevated the B2-microglobulin and $\mathrm{LDH}$ and the others blood tests were within the normal limits. Abdominal radiography was normal. On February 2014 patient underwent to laparotomy due to signs and symptoms of intestinal obstruction. The resected bowel on histopathological examination and Immunohistochemistry (IHC) was diagnosed as Diffuse Large B Cell Lymphoma (DLBCL). Post operation patient received six cycles of CHOP protocol with well tolerance and good response. She did evaluation by whole body Positron Emission TomographyComputed Tomography scan (PET-CT-scan), which appeared multiple mesenteric, largest was $1.4 \mathrm{~cm}$. We recommended to add two cycles of CHOP then we evaluated her after the eighth cycle, whole body positron emission tomography-computed tomography verified complete resolution of the malignancy and the Para clinical where reduced to the normal range for LDH 158, B2- macroglobulin 1.2. The patient was evaluated in regular interval at first every 3 months for the first year then every 6 months after that annually. Follow- up evaluation consisted of interval history and physical examination. The CT scans and tumor marker including ESR, B2-microglobulin, $\mathrm{LDH}$ were used during the follow-up always staying in the normal range. Our patient is complete remission without any complain or any relapse and no distant metastasis according to the last evaluation on September 2021.

\section{Discussion}

Primary gastro-intestinal lymphoma accounts for $1 \%-4 \%$ of all gastrointestinal malignancies [9]. Gastrointestinal lymphoma accounts for $5-10 \%$ of all non-Hodgkin's lymphoma with intestinal lymphoma contributing $15-20 \%$ of all gastrointestinal lymphoma [10]. The gastrointestinal tract is the most common site of extranodal involvement for diffuse large B-cell lymphoma (DLBCL) [11]. Highgrade $\mathrm{B}$ cell lymphoma was the most common subtype in all the patients. This was followed by T cell lymphoma, which is apparently more than in Europe [12]. Majority of these arise in the stomach (up to $65 \%$ of all GI lymphoma) followed by the small bowel (20$30 \%$ ) with rest arising in the colon and rectum [13]. Most common site involving in lymphoma of small intestine is ileum (60\%-65\%) followed by jejunum (20\%-25\%), duodenum (6\%-8\%) [14]. The ileocaecal region was the most common site, with a frequency of $38.3 \%$ [15]. Computed tomography (CT) enterography is a first-line diagnostic method for suspicion of small bowel pathologies [16]. Most of the patients received combined treatment including surgery and chemotherapy with or without radiotherapy [17]. Urgency of surgical operation has also been reported as an important factor affecting survival along with histological subtype where in B cell lymphomas have better prognosis than T cell phenotype [18]. Patient prognosis 
is related to factors that include age, histological subtype, stage at diagnosis and the presence or absence of systemic symptoms [19].

\section{Conclusion}

Lymphoma can be nodal and extranodal. The most typical site of extranodal lymphoma is GIT. Commonly affecting the stomach, Small Intestine (SI), and Large Intestine (LI). DLBCL is an aggressive (fast-growing) and it can develop in the lymph nodes or in "extranodal sites" (areas outside the lymph nodes) such as the gastrointestinal tract, testes, thyroid, skin, breast, bone, brain, or essentially any organ of the body. A diagnosis is often only made after surgical exploration. Surgical resection and chemotherapy have been and remain the mainstays of treatment. Prognosis is often mixed with median survival of above 5 years reported in various series. Our case is complete remission and still alive without any complain or relapses until published this article.

\section{References}

1. Dawson IM, et al. Primary malignant lymphoid tumours of the intestinal tract Report of 37 cases with a study of factors influencing prognosis. $\mathrm{Br} \mathrm{J}$ Surg. 1961; 49: 80-89.

2. López A, et al. Tratamiento de las enfermedades gastroenterológicas. Asociación Española de Gastroenterología. Valencia: Fundación AstraZeneca. 2011: 327-334.

3. Bautista-Quach, et al. Gastrointestinal lymphomas: Morphology immunophenotype, and molecular features. J Gastrointest Oncol. 2012; 3: 209-225

4. Wong MT, Eu KW. Primary colorectal lymphomas. Colorectal Dis. 2006; 8: 586-591.

5. Ruskoné-Fourmestraux A, et al. Primary digestive tract lymphoma: a prospective multicentric study of 91 patients. Groupe d'Etude des Lymphomes Digestifs. Gastroenterology. 1993; 105: 1662-1671.

6. Stanojevic GZ, et al. Primary colorectal lymphoma: an overview. World $\mathrm{J}$ Gastrointest Oncol. 2011; 3: 14-18.
7. Ghimire P, Wu GY, Zhu L. Primary gastrointestinal lymphoma. World J Gastroenterol. 2011; 17: 697-707.

8. Doolabh N, et al. Primary colonic lymphoma. J SurgOncol. 2000; 74: 257262.

9. Yin L, et al. Primary small-bowel non-Hodgkin's lymphoma: A study of clinica features, pathology, management and prognosis. J Int Med Res. 2007; 35: 406-415.

10. Zinzani PL, et al. Primary intestinal lymphoma: clinical and therapeutic features of 32 patients. Haematologica. 1997; 82: 305-308.

11. Swerdlow SH, et al. WHO classification of tumours of haematopoietic and lymphoid tissues. $4^{\text {th }}$ ed. Lyon: IARC. 2008.

12. Koch $P$, et al. Primary gastrointestinal non-Hodgkin's lymphoma: I. Anatomic and histologic distribution, clinical features, and survival data of 371 patients registered in the German Multicenter Study GIT NHL 01/92. J Clin Oncol. 2001; 19: 3861-3873.

13. Gonzalez QH, et al. Primary colonic lymphoma. Am Surg. 2008; 74: 214-216.

14. Schottenfeld D, et al. The Epidemiology and pathogenesis of neoplasia in the small intestine. Ann Epidemiol. 2009; 19: 58-69.

15. Morton JE, et al. Primary gastrointestinal non-Hodgkin's lymphoma: a review of 175 British National Lymphoma Investigation cases. Br J Cancer. 1993; 67: 776-782.

16. Upegui D, et al. Uso de entero-TC para evaluar patología del intestino delgado: experiencias y hallazgos en 90 pacientes. Rev Col Radiol. 2010; 21: $2818-2825$

17. Nakamura S, et al. Primary gastrointestinal lymphoma in Japan: a clinicopathologic analysis of 455 patients with special reference to its time trends. Cancer. 2003; 97: 2462-2473.

18. Zhou JL, et al. The diagnosis and treatment of colorectal non-Hodgkin's lymphoma 32 cases. Zhonghua Wai Ke Za Zhi. 2011; 49: 290-294.

19. Vaidya $R$, et al. Bowel perforation in intestinal lymphoma: incidence and clinical features. Ann Oncol. 2013; 24: 2439-2443. 